\title{
Dosimetric parameters predict radiation- induced choanal stenosis in patients with nasopharyngeal carcinoma
}

\author{
Hui Chang ${ }^{\dagger}$, Kai Chen ${ }^{\dagger}$, Ya-lan Tao, Fei Han, Wei-jun Ye ${ }^{*}$ and Yuan-hong Gao*
}

\begin{abstract}
Background: Radiation-induced choanal stenosis (RICS) severely decreases life quality of patients with nasopharyngeal carcinoma (NPC) and originates from nasal mucositis, which depends on radiation dose. This selfcontrolled study aimed to find the correlations between dosimetric parameters and RICS.

Methods: Totally 49 NPC patients treated with intensity-modulated radiotherapy from May 2010 to Aug. 2013 and diagnosed with RICS during follow-up were enrolled into this study. Minimum point dose, maximum point dose, mean dose (Dmean), dose covering $\geq 33 \%$ volume (D33), dose covering $\geq 66 \%$ volume (D66), and volume receiving $\geq 60$ Gy (V60) were compared between the nasal cavities with and without RICS, through paired t-test. The parameters with difference would enter receiver operating characteristic analysis to determine their cutoff values. Then predicting abilities of the cutoff values were tested by Chi-square test.

Result: The nasal cavities with RICS appeared to have higher Dmean, D33, D66 and V60, compared with those without RICS ( $P$ values were $0.014,0.003,0.006$ and 0.010 ). Dmean $\geq 54.22 \mathrm{~Gy}, \mathrm{D} 33 \geq 61.96 \mathrm{~Gy}, \mathrm{D} 66 \geq 46.50 \mathrm{~Gy}$ and V60 $\geq 48.13 \%$ were demonstrated to be related with a higher risk of RICS.

Conclusion: Dmean, D33, D66 and V60 of nasal cavity might be used as predictors of RICS. Their values needed to be controlled whenever possible, for ameliorating life quality of NPC patients.
\end{abstract}

Keywords: Nasopharyngeal carcinoma, Choanal stenosis, Radiation dose

\section{Introduction}

Nasopharyngeal carcinoma (NPC) is one of the most common malignancies in South China and mainly managed with radiotherapy [1]. The 5-year overall survival of NPC patients has already reached $86.3 \%$, due to advent of intensity-modulated radiotherapy (IMRT) and concurrent chemotherapy (CCT) [2]. Nevertheless, treatment-related late toxicities are still common, especially in those receiving CCT. The incidence of late toxicities was reported to

\footnotetext{
*Correspondence: yewj1968@126.com; gaoyh1969@126.com

${ }^{+}$Co-first authors: Hui Chang, and Kai Chen contributed equally to this work. Department of Radiation Oncology, Sun Yat-sen University Cancer Center; State Key Laboratory of Oncology in South China; Collaborative Innovation Center for Cancer Medicine, 651 Dongfeng Road East, Guangzhou 510060, Guangdong, China
}

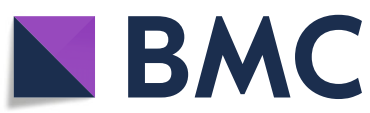

(C) The Author(s). 2020 Open Access This article is licensed under a Creative Commons Attribution 4.0 International License, which permits use, sharing, adaptation, distribution and reproduction in any medium or format, as long as you give appropriate credit to the original author(s) and the source, provide a link to the Creative Commons licence, and indicate if changes were made. The images or other third party material in this article are included in the article's Creative Commons licence, unless indicated otherwise in a credit line to the material. If material is not included in the article's Creative Commons licence and your intended use is not permitted by statutory regulation or exceeds the permitted use, you will need to obtain permission directly from the copyright holder. To view a copy of this licence, visit http://creativecommons.org/licenses/by/4.0/. The Creative Commons Public Domain Dedication waiver (http://creativecommons.org/publicdomain/zero/1.0/) applies to the data made available in this article, unless otherwise stated in a credit line to the data.

be as high as $70.8 \%$. And the incidence of grade $3 / 4$ late toxicities was nearly $11.4 \%[3,4]$. These toxicities are worth paying attention to because of its adverse influences on life quality of long-term survivors.

Radiation-induced choanal stenosis (RICS) is a rare late toxicity observed in only $4.3 \%$ of NPC patients. It leads to serious difficulty in breathing through and discharge from nose. For improving these symptoms, transnasal endoscopic surgery is often needed [5-7]. Ku et al. found that RICS originated from severe choanal mucositis [8]. Since 
degree of head-and-neck mucositis depends on radiation dose $[9,10]$, it is important to control the dose received by nasal cavity, especially the side without tumor infiltration. However, there is no study focusing on the threshold dose to cause RICS. Therefore, we conducted this retrospective, self-controlled study to analyze association between values of dosimetric parameters and RICS onset.

\section{Methods}

\section{Patient selection}

A patient would be involved from clinical database of our hospital and retrospectively reviewed, if he or she had: (i) previously untreated, pathologically diagnosed NPC; (ii) complete course of radiotherapy with IMRT, from May 1st 2010 to Aug. 31st 2013; (iii) unilateral RICS diagnosed by electronic nasopharyngoscope. The cases would be excluded for: (i) prior history of any other nasal/sinusoidal disease or surgery through nasal cavity; (ii) tumor invasion directly into nasal cavities.

\section{Diagnostic and therapeutic procedure}

Before treatment, pathologic diagnosis of each patient was achieved through nasopharyngoscope. Clinical stage was evaluated based on magnetic resonance imaging (MRI) of head and neck, computed tomography (CT) of chest and abdomen, and whole-body bone scan (or positron emission tomography). For convenience of analysis, transformation of stage into the 8th edition of the Union for International Cancer Control/American Joint Cancer Committee TNM classification were made for all the patients.

Early diseases (stage T1-2NOM0) were managed with IMRT alone. Locally advanced diseases (stage T3-4N0M0, T1-4N1-3M0) were managed with IMRT + CCT \pm neoadjuvant chemotherapy (NACT). NACT before radiotherapy was repeated every 3 weeks for 2-3 cycles, with a regimen of docetaxel + cisplatin + fluorouracil or docetaxel + cisplatin. CCT of a single-agent cisplatin was repeated every week for 4-6 cycles, or every 3 weeks for 1-3 cycles. Target delineation and dose prescription of IMRT were done according to the International Commission on Radiation Units and Measurements Report 83. During radiotherapy, nasal cavities were rinsed twice daily, with sterile physiological saline.

\section{Follow-up}

In the first 3 years after treatment, all patients were followed up every 3-6 months, with outpatient interview. At each interview, nasopharyngoscope was performed to detect recurrent primary tumor and RICS. The 22-item sinonasal outcomes test (SNOT-22) score was assessed at diagnosis of RICS. Other examinations included head-and-neck MRI, thoraco-abdominal CT and annual whole-body bone scan (or positron emission tomography). In the 4th and 5th years, follow-up was made every 6-12 months, through outpatient interview or telephone. After the 5th year, the interval of followup became 12 months, until death from NPC or Dec. 31st 2019, whichever came first.

\section{Statistical analysis}

Dosimetric parameters analyzed in this study included minimum point dose (Dmin), maximum point dose (Dmax), mean dose (Dmean), dose covering $\geq 33 \%$ volume (D33), dose covering $\geq 66 \%$ volume (D66), and volume receiving $\geq 60$ Gy (V60). First, these parameters were compared between the sides of normal control (NC) and RICS, by using paired t-test. Second, receiver operating characteristic (ROC) analysis was performed in the parameters exhibiting statistical difference, with each side of nasal cavity as an individual subject, to determine their cutoff values. Third, predicting abilities of the cutoff values were checked by Chi-square test. Statistical procedure of this study referred to Fig. 1. It was completed by GraphPad Prism 6.0 (GraphPad Software, La Jolla, CA, USA) and IBM SPSS Statistics 23.0 (IBM Co., Armonk, New York, US). Difference with a two-sided $P$ value of $<0.05$ was regarded to be statistically significant.

\section{Results \\ Clinical characteristics}

From May 2010 to Aug. 2013, a total of 4745 NPC patients received radiotherapy in our hospital. Of those, 3176 patients were irradiated with IMRT. During the period of follow-up, 61 patients (1.9\%) were found to suffer from RICS, including 49 cases with unilateral RICS. The baseline clinical profiles of the eligible patients were shown in Table 1. Continuous data is presented as median with range, and categorical data is presented as proportions (\%). Among the 49 patients, there were $33(67.3 \%)$ males and $16(32.7 \%)$ females. The median age was 44 (range, 20-71) years old. Case numbers of T3-4 and T1-2 diseases were $40(81.6 \%)$ and 9 (18.4\%), respectively. Chemotherapy was administered in 47 (95.9\%) cases. The prescribed total dose was 70.00 (66.00-74.00) Gy. RICS of right and left sides were seen in $24(49.0 \%)$ and 25 (51.0\%) cases, respectively.

\section{Follow-up outcome}

The median of follow-up period was 78 (range, 56-109) months. There were 4 patients $(8.2 \%)$ lost to follow-up at the 56th, 64th, 65th and 76th months, respectively. Within the 1st year after treatment, there were 44 (89.8\%) RICS. No death happened in this cohort. Local recurrence and bone metastasis happened in 2 (4.1\%) and $1(2.0 \%)$ cases, respectively. Fig. 2 displayed the curves of stenosis-free and disease-free survivals, which were defined as the time period from completion of radiotherapy to onset of corresponding events. 


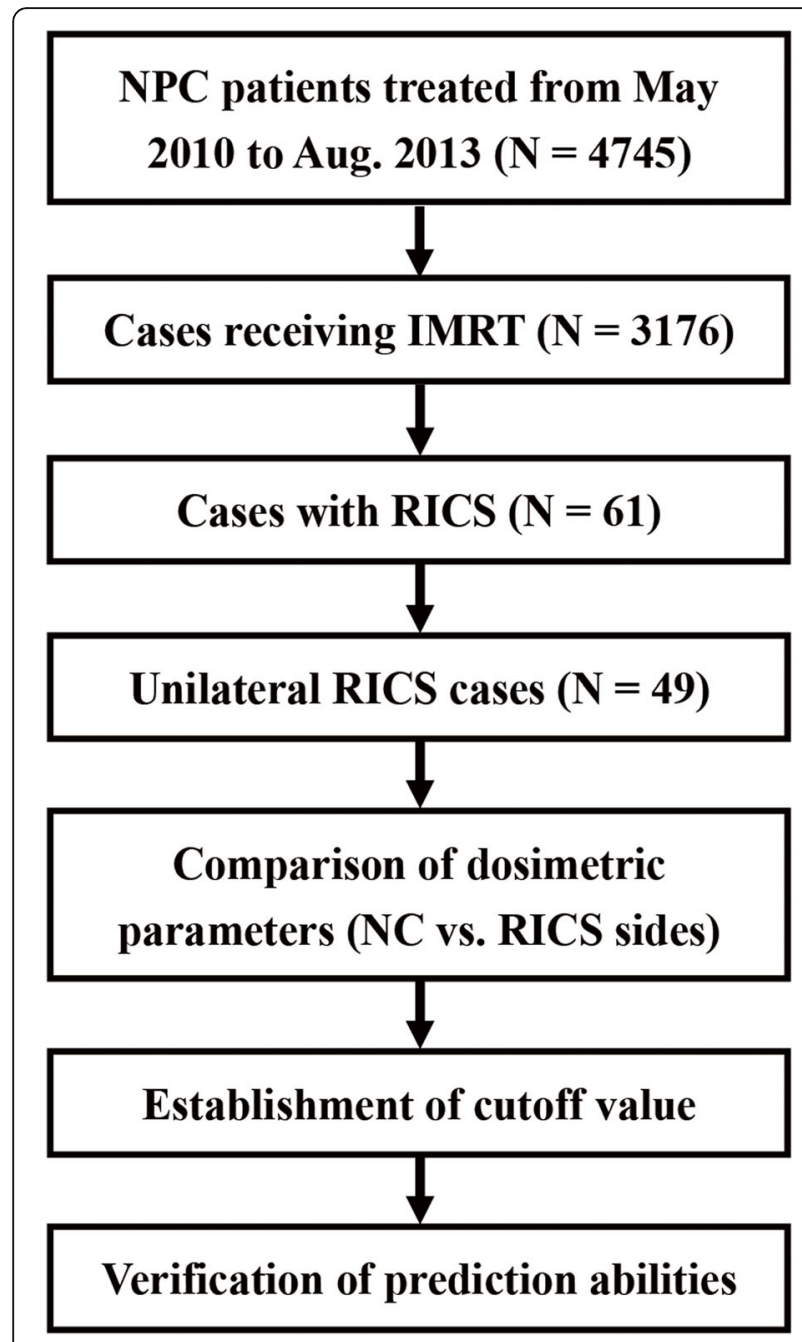

Fig. 1 Process of this study. Abbreviations: NPC, nasopharyngeal carcinoma; IMRT, intensity-modulated radiotherapy; RICS, radiationinduced choanal stenosis; NC, normal control

\section{Dosimetric analysis}

In paired t-test, RICS side of nasal cavities appeared to have higher Dmean, D33, D66 and V60, compared with NC side (Fig. 3). The means of difference ( \pm standard error) were $3.53 \pm 1.38$ Gy $(P=0.014), 2.86 \pm 0.89$ Gy $(P=0.003), 5.65 \pm$ $1.97 \mathrm{~Gy}(P=0.006)$ and $10.29 \% \pm 3.83 \%(P=0.010)$. No significant difference was obtained in Dmin and Dmax.

As previously described, Dmean, D33, D66 and V60 went through ROC analysis (Fig. 4). Their cutoff values for predicting RICS were $54.22 \mathrm{~Gy}, 61.96 \mathrm{~Gy}$, $46.50 \mathrm{~Gy}$ and $48.13 \%$ ( $P$ values were $0.003,0.004$, 0.002 and 0.004$)$, respectively. Then validation on predicting abilities of the cutoff values were validated (Table 2). Through Chi-square test, Dmean $\geq 54.22$ Gy, D33 $\geq 61.96$ Gy, D $66 \geq 46.50$ Gy and V60 $\geq 48.13 \%$ appeared to predict RICS ( $P$ values were $0.001,0.004$, $<0.001$ and 0.001 ).
Table 1 Baseline clinical profiles of the 49 patients with radiation-induced choanal stenosis

\begin{tabular}{ll}
\hline Characteristic & Value \\
\hline Age at diagnosis (range) / years old & $44(20-71)$ \\
No. of patients by gender & \\
Male & $33(67.3 \%)$ \\
Female & $16(32.7 \%)$ \\
No. of patients by T stage & \\
T4 & $11(22.4 \%)$ \\
T3 & $29(59.2 \%)$ \\
T2 & $7(14.3 \%)$ \\
T1 & $2(4.1 \%)$ \\
No. of patients by N stage & \\
N3 & $5(10.2 \%)$ \\
N2 & $26(53.1 \%)$ \\
N1 & $18(36.7 \%)$ \\
N0 & $0(0.0 \%)$
\end{tabular}

No. of patients by WHO pathologic subtypes

$\begin{array}{ll}\text { I-I } & 0(0.0 \%) \\ \text { II } & 100(100.0 \%)\end{array}$

No. of patients by prior allergic rhinitis

$$
\begin{array}{ll}
\text { Yes } & 3(6.1 \%) \\
\text { No } & 46(93.9 \%)
\end{array}
$$

No. of patients by chronic smokers

Yes $9(18.4 \%)$

No

$40(81.6 \%)$

No. of patients by treatment modes

$$
\begin{array}{ll}
\mathrm{RT} & 2(4.1 \%) \\
\mathrm{RT}+\mathrm{CCT} & 12(24.5 \%) \\
\mathrm{NACT}+\mathrm{RT}+\mathrm{CCT} & 35(71.4 \%)
\end{array}
$$

Prescribed total dose (range) / Gy $\quad 70.00$ (66.00-74.00) Prescribed single dose (range) / Gy $\quad 2.19$ (2.06-2.34)

Actual maximum GTV dose (range) / Gy $\quad 77.22$ (73.77-83.50) Actual minimum GTV dose (range) / Gy $\quad 69.79$ (65.27-72.59) Actual mean GTV dose (range) / Gy $\quad 73.75$ (65.80-78.66)

No. of patients by RICS sides

\begin{tabular}{ll} 
Right & $24(49.0 \%)$ \\
Left & $25(51.0 \%)$ \\
SNOT-22 score (range) & $17(11-59)$ \\
\hline
\end{tabular}

Abbreviations: WHO World Health Organization, $R T$ radiotherapy, CCT concurrent chemotherapy, NACT neoadjuvant chemotherapy, GTV gross tumor volume, RICS radiation-induced choanal stenosis, SNOT-22 22-item sinonasal outcomes test

\section{Discussion}

At diagnosis of RICS, the median SNOT-22 score of our cohort was 17 (range, 11-59). It is known that SNOT-22 score is the most widely accepted and best validated tool for evaluating life quality of patients with chronic 

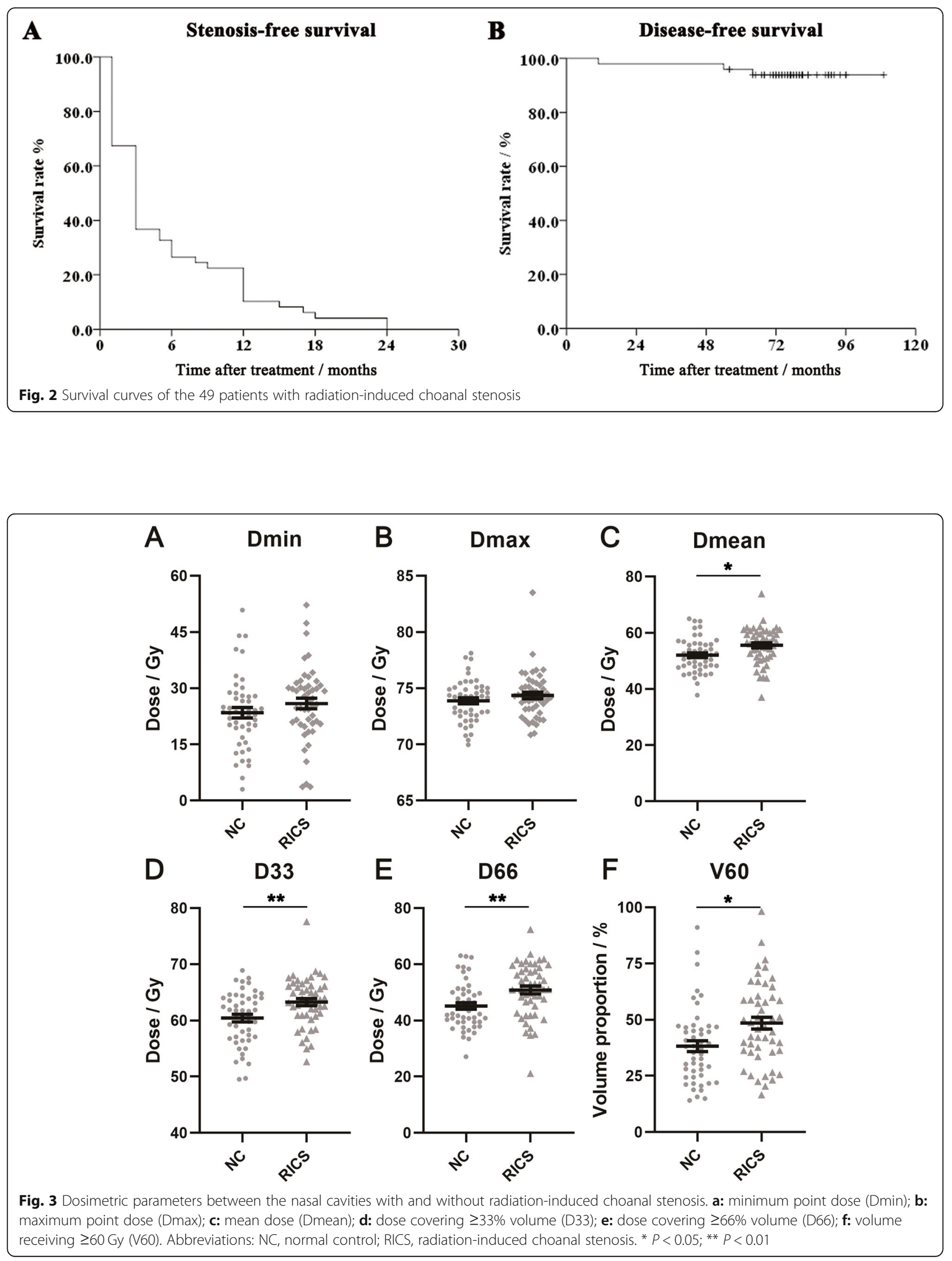


\section{A}

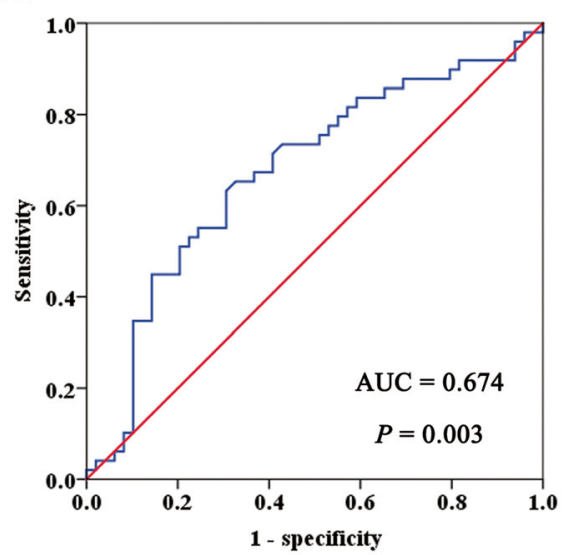

C

D66

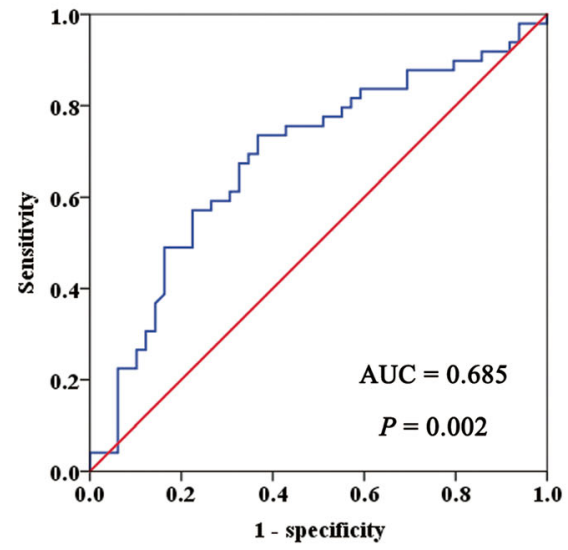

B

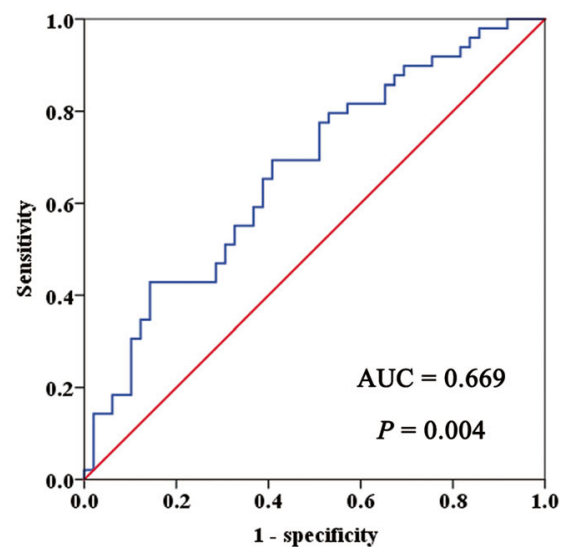

D

V60

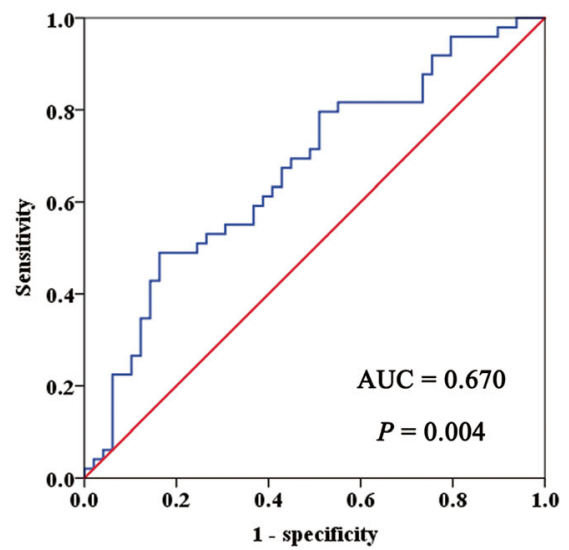

Fig. 4 Receiver operating characteristic curves of dosimeric parameters on predicting radiation-induced choanal stenosis. a: mean dose (Dmean); b: dose covering $\geq 33 \%$ volume (D33); c: dose covering $\geq 66 \%$ volume (D66); d: volume receiving $\geq 60$ Gy (V60). Abbreviations: AUC, area under curve

Table 2 Prediction validation of dosimetric parameters on radiation-induced choanal stenosis

\begin{tabular}{|c|c|c|c|c|c|}
\hline & & $\mathrm{NC}$ & $\mathrm{RICS}$ & Chi-square & $P$ value \\
\hline \multirow[t]{2}{*}{ Dmean / Gy } & $<54.22$ & $34(69.4 \%)$ & $18(36.7 \%)$ & 10.48 & 0.001 ** \\
\hline & $\geq 54.22$ & $15(30.6 \%)$ & $31(63.3 \%)$ & & \\
\hline \multirow[t]{2}{*}{ D33 / Gy } & $<61.96$ & $29(59.2 \%)$ & 15 (30.6\%) & 8.084 & $0.004 * *$ \\
\hline & $\geq 61.96$ & $20(40.8 \%)$ & $34(69.4 \%)$ & & \\
\hline \multirow[t]{2}{*}{ D66 / Gy } & $<46.50$ & $31(63.3 \%)$ & $13(26.5 \%)$ & 13.36 & $<0.001 * *$ \\
\hline & $\geq 46.50$ & 18 (36.7\%) & $36(73.5 \%)$ & & \\
\hline \multirow[t]{2}{*}{ V60 / \% } & $<48.13$ & $41(83.7 \%)$ & $25(51.0 \%)$ & 11.87 & $0.001 * *$ \\
\hline & $\geq 48.13$ & 8 (16.3\%) & $24(49.0 \%)$ & & \\
\hline
\end{tabular}

Abbreviations: NC normal control, RICS radiation-induced choanal stenosis, Dmean mean dose, $D 33$ dose covering $\geq 33 \%$ volume, $D 66$ dose covering $\geq 66 \%$ volume, $V 60$ volume receiving $\geq 60 \mathrm{~Gy}$. ${ }^{* *} P<0.01$ rhinosinusitis. According to studies by Erskine et al. and Rudmik et al., the median SNOT-22 score in healthy population was 8 (range, 2-17). When SNOT-22 score reached 10,30 and 50 , the probability to receive endoscopic surgery increased to $37.5,55.6$ and $75.0 \%$, respectively $[11,12]$. In other words, RICS could bring seriously deteriorated life quality to NPC patients and should be avoided whenever possible. Compared with conventional 2- and 3-dimensional radiotherapy, IMRT has been proven to obviously decrease incidences of the common late toxicities in NPC patients, including xerostomia, hearing loss, trismus and temporal lobe neuropathy $[13,14]$. Before this study, Shemesh et al. found 4 (4.3\%) cases harboring RICS from 93 patients treated with both 2dimensional radiotherapy and IMRT [5]. Through reviewing 3176 patients treated with IMRT uniformly, this study showed a lower incidence of RICS (1.9\%). Thus, it is necessary and probable to reduce RICS through IMRT, which has a superiority in dose control. 
Prior studies indicated that dosimetric parameters could predict degree of head-and-neck mucositis, which might later transformed into adhesive diseases of mucosa, such as RICS. In a study by Mazzola et al., oral mucositis of grade $\geq$ 2 was related to Dmean ( $\geq 50$ Gy), Dmax ( $\geq 65$ Gy), V45 (> $40 \%$ ), V50 (> 30\%) and V55 (> 20\%) [9]. In a study by Musha et al., Dmax was confirmed to be associated with grade 2-3 oral mucositis. Moreover, the threshold value was discovered to vary for different sites. For palate and tongue, the figures were 43.0 and $54.3 \mathrm{~Gy}$, respectively [10]. In literrature, there was merely one study directly reporting the correlation between radiation dose and nasal mucositis. Riva et al. discovered that elevated Dmean and D2 were associated with a higher incidence of nasal mucositis [15]. But the severity was not discussed in that study. And the sample size of this study was quite small.

This study made the first approach to how radiation dose affected RICS. Here we revealed that nasal cavity with RICS underwent greater radiation dose than that without RICS. Higher dosimetric parameters were observed in the RICS side, including Dmean $(55.54 \pm 0.93$ vs. $52.01 \pm 0.86 \mathrm{~Gy}, P=0.014)$, D33 $(63.29 \pm 0.63$ vs. $60.43 \pm 0.68$ Gy, $P=0.003)$, D66 (50.85 \pm 1.37 vs. $45.20 \pm$ $1.19 \mathrm{~Gy}, P=0.006)$ and V60 $(48.50 \pm 2.60 \%$ vs. $38.21 \pm$ $2.41 \%, P=0.010)$. Unexpectedly, Dmax of the RICS side was similar to that of the NC side $(74.35 \pm 0.30$ vs. $73.88 \pm 0.27, P=0.273)$. Next, we further established cutoff value of these parameters for predicting RICS. Patients with Dmean $\geq 54.22$ Gy, D33 $\geq 61.96$ Gy, D66 $\geq$ $46.50 \mathrm{~Gy}$ and $\mathrm{V} 60 \geq 48.13 \%$ emerged to be at a higher risk to develop RICS. Among these parameters, D66 had the best sensitivity $(73.5 \%)$ and negative predictive value (70.5\%). V60 had the best specificity (83.7\%) and positive predictive value (75.0\%). This study provided a reference for dose control of nasal cavity without invasion or approximation of tumor. Its results were based on a cohort with a relatively large sample size. And self-controlled design averted biases brought by imbalance of baseline characteristics. These were the strengths of our study.

It was noteworthy that in this study, $89.8 \%$ of RICS happened within the 1st year after radiotherapy. Similarly, the 4 cases presented by Shemesh et al. had RICS in 2-12 months [5]. And in the 6 cases presented by Ku et al., the mean time to RICS was 10.5 months [8]. So it could be inferred that this period was critical for controlling nasal mucositis and RICS formation. Up to now, saline rinsing was the only effective method supported by strong evidences to manage chronic nasal mucositis [16]. On basis of our results, nasal saline rinsing was suggested to be carried out during radiotherapy and until at least 1 year after. Recently, Canakci et al. found in rat models that local application of Nigella sativa oil could relieve radiationinduced erosion of nasal mucosa [17]. Duan also found in pig models that mesenchymal stem cells from human umbilical cord could alleviate mucosal edema caused by radiotherapy and improve mucus clearance [18]. These methods might become treatment choices of nasal mucositis in future. In addition, smoking and poor nutritional condition was demonstrated to increase serious severe oral mucositis $[19,20]$. Quitting smoking and nutritional support might be helpful for prevention of RICS.

Indeed, this study had 3 main disadvantages, due to rarity of RICS. First, it was a retrospective study. Second, it was an observational study without active intervention in radiation dose. Third, it had no verification in an independent cohort. Hence, the results of this study needed to be popularized with caution and externally validated by prospective randomized controlled trials.

\section{Conclusion}

Dmean, D33, D66 and V60 of nasal cavity could act as predictors of RICS. For ameliorating life quality of NPC patients, the values of these dosimetric parameters should be controlled whenever possible.

\section{Abbreviations \\ NPC: Nasopharyngeal carcinoma; IMRT: Intensity-modulated radiotherapy; CCT: Concurrent chemotherapy; RICS: Radiation-induced choanal stenosis; MRI: Magnetic resonance imaging; CT: Computed tomography; \\ NACT: Neoadjuvant chemotherapy; SNOT-22: 22-item sinonasal outcomes test; Dmin: Minimum point dose; Dmax: Maximum point dose; Dmean: Mean dose; D33: Dose covering $\geq 33 \%$ volume; D66: Dose covering $\geq 66 \%$ volume; V60: Volume receiving $\geq 60 \mathrm{~Gy}$; NC: Normal control; ROC: Receiver operating characteristic}

\section{Acknowledgements \\ None.}

Authors' contributions

All authors read and approved the final version of the manuscript. Idea and conception: HC, KC, WY, YG. Data collection: KC, YT, FH. Data interpretation: $\mathrm{HC}, \mathrm{FH}, \mathrm{WY}, \mathrm{YG}$. Manuscript writing: HC, KC, YT.

\section{Funding}

This study was supported by the Science and Technology Planning Project of Guangdong Province, China; Grant numbers: 2017A020215157. The funding sources had no role in the study design, data collection, analysis, interpretation, or writing of the manuscript.

\section{Availability of data and materials}

The data that support the findings of this study are available from the corresponding author upon reasonable request.

\section{Ethics approval and consent to participate}

This study was approved by the Institutional Review Board of the Sun Yatsen University Cancer Center. All methods were carried out in accordance with relevant guidelines and regulations.

\section{Consent for publication}

Not applicable.

Competing interests

The authors declare that they have no competing interests. 
Received: 17 February 2020 Accepted: 10 March 2020

Published online: 05 June 2020

\section{References}

1. Chen YP, Chan ATC, Le QT, Blanchard P, Sun Y, Ma J. Nasopharyngeal carcinoma. Lancet. 2019;394(10192):64-80.

2. Tang LL, Liang SB, Huang CL, Zhang F, Xu C, Mao YP, et al. The development and external validation of simplified $T$ category classification for nasopharyngeal carcinoma to improve the prognostic value in the intensity-modulated radiotherapy era. Cancer Med. 2019;8(5):2213-22.

3. Chen BB, Lu SY, Peng H, Sun FF, Zhu J, Wang J, et al. Comparison of Long Term Outcomes and Sequelae Between Children and Adult Nasopharyngeal Carcinoma Treated With Intensity Modulated Radiation Therapy. Int J Radiat Oncol Biol Phys. 2020;106(4):848-56.

4. Zhang Y, Chen L, Hu GQ, Zhang N, Zhu XD, Yang KY, et al. Gemcitabine and Cisplatin induction chemotherapy in nasopharyngeal carcinoma. N Engl J Med. 2019;381(12):1124-35.

5. Shemesh R, Alon EE, Gluck I, Yakirevitch A. Endoscopic surgery for delayed Sinonasal complications of radiation therapy for nasopharyngeal carcinoma: a subjective outcome. Int J Radiat Oncol Biol Phys. 2018;100(5):1222-7.

6. Alon EE, Lipschitz N, Bedrin L, Gluck I, Talmi Y, Wolf M, et al. Delayed Sinonasal complications of radiotherapy for nasopharyngeal carcinoma. Otolaryngol Head Neck Surg. 2014;151(2):354-8.

7. Wang QY, Wang SQ, Lin S, Chen HH, Lu YY, et al. Transnasal endoscopic repair of acquired posterior choanal stenosis and atresia. Chin Med J. 2008; 121(12):1101-4.

8. Ku PK, Tong MC, Tsang SS, van Hasselt A. Acquired posterior choanal stenosis and atresia: management of this unusual complication after radiotherapy for nasopharyngeal carcinoma. Am J Otolaryngol. 2001;22(4):225-9.

9. Mazzola R, Ricchetti F, Fersino S, Fiorentino A, Levra NG, Paolo GD, et al. Predictors of mucositis in oropharyngeal and oral cavity cancer in patients treated with volumetric modulated radiation treatment: a dose-volume analysis. Head Neck. 2016;38(Suppl 1):E815-9.

10. Musha A, Shimada H, Shirai K, Saitoh J, Yooko S, Chikamatsu K, et al. Prediction of acute radiation Mucositis using an Oral mucosal dose surface model in carbon ion radiotherapy for head and neck tumors. PLoS One. 2015;10(10):e0141734.

11. Erskine SE, Hopkins C, Clark A, Anari S, Kumar N, Robertson A, et al. SNOT-22 in a control population. Clin Otolaryngol. 2017;42(1):81-5.

12. Rudmik L, Soler ZM, Mace JC, DeConde AS, Schlosser RJ, Smith TL. Using preoperative SNOT-22 score to inform patient decision for endoscopic sinus surgery. Laryngoscope. 2015;125(7):1517-22.

13. Zhang B, Mo Z, Du W, Wang Y, Liu L, Wei Y. Intensity-modulated radiation therapy versus 2D-RT or 3D-CRT for the treatment of nasopharyngeal carcinoma: a systematic review and meta-analysis. Oral Oncol. 2015;51(11):1041-6.

14. Qiu WZ, Peng XS, Xia HQ, Huang PY, Guo X, Cao KJ. A retrospective study comparing the outcomes and toxicities of intensity-modulated radiotherapy versus two-dimensional conventional radiotherapy for the treatment of children and adolescent nasopharyngeal carcinoma. J Cancer Res Clin Oncol. 2017:143(8):1563-72.

15. Riva G, Franco P, Provenzano E, Arcadipane F, Bartoli C, Lava P, et al. Radiation-induced rhinitis: cytological and olfactory changes. Am J Rhinol Allergy. 2019;33(2):153-61.

16. Harvey R, Hannan SA, Badia L, Scadding G. Nasal saline irrigations for the symptoms of chronic rhinosinusitis. Cochrane Database Syst Rev. 2007;3:CD006394.

17. Çanakci H, Yilmaz AAŞ, Canpolat MS, Şeneldir H, Kir G, Eriş AH, et al. Evaluation of the effect of topical application of Nigella sativa on acute radiation-induced nasal Mucositis. J Craniofac Surg. 2018;29(3):e279-82.

18. Duan HG, Ji F, Zheng CQ, Wang CH, Li J. Human umbilical cord mesenchymal stem cells alleviate nasal mucosa radiation damage in a guinea pig model. J Cell Biochem. 2015;116(2):331-8.

19. Eilers J, Million R. Clinical update: prevention and management of oral mucositis in patients with cancer. Semin Oncol Nurs. 2011;27(4):e1-e16.

20. Chen SC, Lai YH, Huang BS, Lin CY, Fan KH, Chang JT. Changes and predictors of radiation-induced oral mucositis in patients with oral cavity cancer during active treatment. Eur J Oncol Nurs. 2015;19(3):214-9.

\section{Publisher's Note}

Springer Nature remains neutral with regard to jurisdictional claims in published maps and institutional affiliations.

Ready to submit your research? Choose BMC and benefit from:

- fast, convenient online submission

- thorough peer review by experienced researchers in your field

- rapid publication on acceptance

- support for research data, including large and complex data types

- gold Open Access which fosters wider collaboration and increased citations

- maximum visibility for your research: over $100 \mathrm{M}$ website views per year

At $\mathrm{BMC}$, research is always in progress.

Learn more biomedcentral.com/submissions 